\title{
Tarıma Dayalı Sanayi İşletmelerinin Ar-Ge Potansiyelinin İncelenmesi: Çanakkale İli Örneği
}

\section{Investigation of R\&D Potential of the Agricultural Industry Firms: Çanakkale Province Case}

\author{
Assoc. Prof. Dr. Sibel Tan (Çanakkale Onsekiz Mart University, Turkey) \\ Cansu Tepeli (Çanakkale Onsekiz Mart University, Turkey) \\ Dr. Bengü Everest (Çanakkale Onsekiz Mart University, Turkey)
}

\begin{abstract}
Recently, national economy has an important role in level of development and in steadily increase of the level of production. Research and Development is the use of background information and an intensive effort with a systematic base in new technologies in order to increase fund of knowledge. For the sake of this purpose, the importance given to R\&D studies has been increased both in all over the world. When these countries examined, sources are used efficiently thanks to these activities. In addition to this, R\&D has been an indispensable factor in the competition environment. Çanakkale belonging to the second group out of five in the socio-economic development framework is one of the prominent provinces in terms of development level. Thanks to being the building stone, Çanakkale is expected to give the needed importance R\&D studies to increase its own agricultural competition capacity to gain economical added value. In this study, it is aimed to examine the overall position of the provincial $R \& D$ activities, the number of the enterprises running $R \& D$ activities, the capacity of the enterprises, their business segment, their position in agricultural industry, the importance given to the R\&D activities in agricultural industry thanks to the questionnaires done with 153 enterprises taken from the industrial scaling of Çanakkale Provincial Directorate of Science Industry and Technology.
\end{abstract}

\section{Giriş}

Dünyada gittikçe yaygınlaşan küresel rekabet çerçevesinde bilimsel ve teknolojik gelişmeler ekonomik gelişmeyi hızlandırmada temel araç olarak karşımıza çıkmaktadır. Toplumların ekonomik, sosyal ve kültürel gelişmişlikleri bilimsel ve teknolojik gelişmeleri ile doğrudan ilişkilidir. Bu kapsamda tüm dünyada ve ülkemizde bilgi ekonomisi kavramı giderek önem kazanmıştır. Bilgi ekonomisi; toplumun ve organizasyonların bilginin üretimi, dağılımı ve tüketiminde kaynakları nasıl tahsis ettiğini inceleyen bir disiplindir. Bilgi ekonomisi çalışmaları, bilgi yoğun yeni ürün ve hizmetlerin üretimindeki fonksiyonuna odaklanır (Kavak, 2009).

İnsanlık için Ar-Ge faaliyetleri yani yenilik veya buluşun anlamı sadece firma bazında ekonomik amaçlı ürün geliştirilmesi ve buna bağlı refah artırıcı işlemlerin çok ötesinde, hastalıklara yeni tedavi yöntemleri geliştirilmesi, enerji, su, gıda, çevre vb. küresel sorunlar için yeni çözüm yolları bulunması, yeni iletişim yolları veya güvenlik araçları keşfedilmesi gibi daha geniş kitleleri ilgilendiren açılımlara sahiptir. Bu nedenle insanlık Ar-Ge faaliyetlerine aralıksız ve artan ölçüde devam etmekte olup, bu alanda söz sahibi olmayı başaran ülkeler, küresel anlamda ekonomik ve siyasal olarak da üstünlük sağlayabilmektedir (Akbulak ve Akbulak, 2015).

Tüm gelişmiş ülkelerde bilgi ekonomisinin hüküm sürdüğü günümüzde ekonomik sektörlerin tamamında Ar-Ge ve inovasyon kavramları giderek yaygınlaşmıştır. Bu kapsamda ortaya çıkan Ar-Ge çalışmaları sanayi işletmelerinde, büyümenin, üretim artışı sağlamanın ve piyasa koşulları içerisinde ayakta kalabilmenin unsuru olma konumundadır. Ar-Ge; bilimsel ve teknik bilgi düzeyinin arttırılması amacı ile belli bir sisteme dayalı ve düzenli gerçekleştirilen çalışmalar bütünü olarak nitelendirilmektedir (Erkek, 2011).

Ülkeler ürettiği bilgi, geliştirdiği teknoloji ve yenilikler ölçüsünde dünyada söz sahibi olmaktadır. Bu yüzden Türkiye; Dünya ülkeleri ile rekabet edebilmek, ithal etmek yerine kendi teknolojisini geliştirmek ve kullanmak, gelişmiş ülkelere bağımlı kalmamak, gıda güvenliğini sağlamak için Ar-Ge çalışmaları yapmak zorundadır. Gelişmiş ülkeler Ar-Ge harcamaları için bütçelerinden Gayri Safi Yurtiçi Hasılasının (GSYH) yaklaşık \%2'si oranında pay ayırmaktadırlar. Türkiye'de bu oran \%0,95 olup, 2023 yılında \%3'e ulaşması hedeflenmektedir (Anonim, 2015a).

Türkiye'de 2023 hedeflerine ulaşmak amacıyla bir çok politik düzenleme yapılmıştır. Özellikle ihracatın \%20'sinin orta ve yüksek teknoloji ürünlerinden oluşması hedefi doğrultusunda yeni, yenilikçi, rekabet üstünlüğü olan, katma değeri yüksek ve teknoloji tabanlı ürünler ile üretim yöntemleri geliştirmenin yanında, geleneksel imalat sanayimizin de bu yönde değişim ve dönüşümünün sağlanması bakımından ihtiyacımız olan bilgi ve teknolojinin ülkemizde üretilmesi hedeflenmiştir (Anonim, 2013). Dolayısıyla ihracatımızda geleneksel tarım ürünlerinin ve işlenmiş tarım ürünlerinin aldığı pay düşünüldüğünde konunun önemi anlaşılmaktadır.

Bilgi ekonomisinin ön plana çıktığı ve teknoloji odaklı üretim politikalarının uygulandığı günümüzde diğer tüm sektörlerde olduğu gibi tarım sektöründe de Ar-Ge çalışmaları sektörün geleceği ve rekabet şansı açısından son 
derece önemlidir. Ar-Ge faaliyetleri ile ülkelerin yapı taşlarından biri olan tarım ve bunun bir sonucu olan tarıma dayalı sanayi alanında gerekli çalışmaların gerçekleştirilip Türkiye gibi tarım ülkesi olarak geçimini sürdüren ülkelerin rekabet güçlerini arttırmaları açısından son derece önemlidir. Tarıma dayalı sanayide gerekli $\mathrm{Ar}-\mathrm{Ge}$ çalışmalarının üretim modellerine uygulanması ile istihdamın sürekliliği sağlanacak, üretici ve sanayici ile devlet arasında kazancın çift taraflı arttııılı̆ğı, toplumsal refahın sağlandığı bir ekonomi modeli gerçekleşecektir.

Türkiye'de tarım ve gıda sektörünün ülkenin genel ekonomik kalkınmasına kayda değer biçimde katkı sağlama potansiyeli mevcuttur. Ancak ülkenin bunu gerçekleştirme kabiliyeti çoğunlukla verimlilik artışına dayanmaktadır. Tarımda ulusal ve uluslararası düzeyde rekabet şansının artırıması için, temel zorunluluklarından biri tarımın geleneksel olarak oynadığı tampon rolünün üstesinden gelinmesi olacaktır (Anonim, 2016a).

Gelişmekte olan bir çok ülke gibi, Türkiye de sanayileşme yolunda doğal kaynaklardan en üst düzeyde yararlanmak durumundadır. Bu bakımdan tarım sektörü, Türkiye ekonomisine önemli katkılar sağlamaktadır (Demirbaş, 2004). Fakat Türkiye'de tarıma dayalı sanayi sektöründe Ar-Ge faaliyetinde bulunan işletme sayısının oldukça düşük olduğu görülmektedir.

Verimli toprak özelliği, bitkisel üretime uygun arazi mevcudu ve elverişli iklimi sayesinde Türkiye'de tarım sektörü çok çeşitli bir üretim desenine sahiptir. Buna ek olarak tarım ve tarımsal sanayi kuruluşları içerisinde süt ve süt ürünleri, unlu mamüller, tütün, deri, kağıtt, tekstil gibi sektörler tarımsal ekonomide önemli paya sahiptirler. Türkiye ekonomisinin tarihsel sürecinde sanayi ve hizmet sektörlerinin GSYIH'den (Gayrisafi Yurtiçi Hasıla) aldığı pay artmış, tarım sektörünün aldığı pay ise gerilemiştir. Genel bir değerlendirme yapıldığında tarımın Türkiye ekonomisindeki öneminin nispi olarak azalma gösterdiğini söylemek mümkündür. Cumhuriyetin kurulduğu yıllarda tarımın GSYIH'deki payı \%42,8 iken 1970'li yıllarda \%36,0, 1985 yılında \%25,0, 1990 yılında $\% 16,0,2000$ yılında \%13,5 oranında gerçekleşmiştir. Günümüzde ise tarımın GSYİH'deki payı \%9,0'dur (Anonim, 2016b).

Çanakkale ilinde tarımsal faaliyetlerin yoğun olarak yapılmasına bağlı olarak tarıma dayalı sanayi ilerlemiş ve sanayinin ekonomideki payı artmıştır. İl merkezi ve ilçelerinde bulunan işletmeler en fazla süt ve süt ürünleri, zeytinyağı, meyve-sebze işleme, unlu mamuller gibi alanlarda yoğunlaşmış̧ır. Ekonominin yapı taşlarından olan bu faaliyetlerin Ar-Ge çalışmaları ile desteklenmesinin, ilin ekonomik gelişiminde ve teknolojik alt yapısının ilerlemesinde etkili olacağ 1 şüphesizdir.

Çanakkale'de sürdürülen başlıca ekonomik etkinlikler ve yürütülmekte olan sanayi sektörü faaliyetleri tarıma dayalıdır. İl halkının \%70'i ekonomik varlığını tarımsal üretim yaparak sağlamaktadır. İlin önde gelen tarımsal ürünleri; domates, elma, buğday, bakla ve ayçiçeğidir. Çanakkale tarıma elverişli arazileri ve iklimi ile meyve ve sebze üretimine oldukça elverişli durumdadır. Tarımsal üretim verilerine göre 2016 yılında Çanakkale'de üretim yapılan tarım arazisi 284.324 hektardır. İlin bitkisel ürün değeri 1.871 .511 bin TL, hayvansal ürün değeri 418.390 bin TL'dir. İlin tarıma dayalı sanayisi ve üretim verilerine göre pazarlanan ürünler toplamının \%40,17'sini meyveler, \%34,76'sını sebzeler, \%25,07'sini ise tarla ürünleri oluşturmaktadır (Anonim, 2016c).

Çanakkale'de piyasa değeri yüksek ürünlerin sanayi işletmelerinde katma değeri arttırılarak pazarda etkin rol oynaması sağlanmaktadır. Tarıma dayalı sanayide sayıca en fazla olan işletme 442 adet ile süt ve süt ürünleri işletmesidir. Hayvancılık faaliyetlerinin yoğun olarak yapılmasına bağlı olarak bu sektör ön plana çıkmıştır. Bu sektörü izleyen diğer işletmeler 267 adet olan unlu mamüller işletmeleri ve 227 adet olan ekmek ve ekmek çeşitleri üreten işletmelerdir. $\mathrm{Bu}$ işletmeler üretim-tüketim zincirine katkıda bulunarak ilin ekonomisine katkı sağlamaktadır (Anonim, 2015b).

Türkiye'de tarımın ekonomiye katkısında önemli rol oynayan Çanakkale'nin, tarım sektörü rekabet gücünün arttırılmasında Ar-Ge çalışmaları önemli rol oynamaktadır.

Çanakkale'de tarıma dayalı sanayinin Ar-Ge potansiyelinin belirlenmesi ve bu potansiyelin geliştirilmesine yönelik öneriler sunmak amacıyla hazırlanan bu çalışmanın ikinci bölümünde materyal ve yöntem verilmiş, üçüncü bölümünde araştırma bulguları irdelenmiş ve dördüncü bölümde bu bulgulardan varılan sonuçlar ve öneriler sunulmuştur.

\section{Materyal ve Yöntem}

\subsection{Materyal}

Araştırmanın ana materyalini Çanakkale ilindeki tarıma dayalı sanayi işletmelerinden anket yoluyla elde edilen veriler oluşturmaktadır. İşletmelere ilişkin veriler Çanakkale ilinin tüm ilçelerinden elde edilmiştir. Araştırmada birincil ve ikincil verilerden yararlanılmış olup, anket sonucu elde edilen veriler birincil verileri oluşturmaktadır. Araştırmanın ikincil verilerini, konuyla ilgili çeşitli kurum ve kuruluşların yapmış oldukları yayınlar ile diğer araştırmacılar tarafindan yapılmış ve sonuçlanmış olan araştırma sonuçları, resmi istatistikler, derleme, inceleme ve tezlerden elde edilen veriler oluşturmuştur.

\subsection{Yöntem}

Çalışmada Güney Marmara Kalkınma Ajansı tarafından desteklenen "Çanakkale İlinde Sanayi Envanterinin Oluşturulması, İl Sanayisinin Ar-Ge, Yenilikçilik ve Kümelenme Potansiyelinin Araştırılması Projesi” kapsamında 
oluşturulan sanayi veri tabanından tarımsal faaliyet yapılan işletmeler seçilmiş ve örnekleme bu populasyon üzerinden yapılmıştır. $\mathrm{Bu}$ envanterde yer alan 352 tarıma dayalı sanayi işletmesi araştırmanın populasyonunu oluşturmaktadır. Örnek hacmi oransal örnekleme yöntemine dayalı olarak 153 olarak belirlenmiştir.

Anket yapılacak işletme seçiminde \%90 güven aralığında, 0,05 hata payı ile yapılan örneklemede oransal örnekleme formülünden yararlanılmıştır (Miran, 2002).

$$
n=\frac{N p(1-p)}{(N-1) \sigma_{\hat{p}_{X}}^{2}+p(1-p)}
$$

Yapılan örnekleme ile yapılacak anket sayısı 153 olarak belirlenmiştir. Örneğe çıkan işletmelerin bulunduğu ilçe ve köylere gidilerek, daha önceden araştırmanın amacına uygun olarak hazırlanmış bulunan anket formları işletme yöneticileriyle karşılıklı görüşmek yoluyla bizzat araştırıcı tarafından doldurulmuştur.

Araştırma alanında örneğe giren her işletme yetkilisi için doldurulan anketler ayrı ayrı gözden geçirilerek gerekli kontrol ve hesaplamalar yapılmış ve veriler SPSS paket programlarına aktarılarak ortalamalar, yüzdeler, Ki-kare analizi gibi istatistiksel yöntemler kullanılarak analiz edilmiştir. Ki-kare, bir ana kitlenin iki sınıflandırma kriterine göre farklılık gösterme veya birbirinden bağımsız olma hipotezini test etmede kullanılır. Bağımsızlık testlerinde tek bir ana kitle vardır. Bu ana kitle iki kritere göre sınıflandırılır. Bir kritere göre dağılım, diğer bir kritere göre dağılıma hiçbir şekilde bağlı değilse, iki sınıflandırma kriterinin birbirinden bağımsız olduğu düşünülür (Miran, 2002).

\section{Araştırma Bulguları}

\section{1 İnsan Kaynakları ile İlgili Bulgular}

Çanakkale ilinde tarıma dayalı sanayinde Ar-Ge potansiyelinin belirlenmesi amacıyla yapılan bu çalışmada örnek olarak seçilen 153 işletmede tüm çalışanların ve Ar-Ge personelinin eğitim durumları Tablo 1.'de gösterilmiştir. Tabloya göre seçilen işletmelerde 189 kadın, 352 erkek olmak üzere toplam 541 kişi çalışmaktadır. Diğer taraftan bu işletmelerde 11 kadın, 59 erkek olmak üzere toplam 70 Ar-Ge personeli görev yapmaktadır. Bu değerler toplam çalışanlar içerinde Ar-Ge personelinin oranın \%13 civarında olduğunu göstermektedir. Çalışanların eğitim durumları incelendiğinde sırasıyla ortaokul $(\% 39,74)$, ilkokul $(\% 27,91)$ ve lise $(\% 20,89)$ şeklinde yoğunlaşmaktadır. Diğer taraftan Ar-Ge personelinin eğitim durumu incelendiğinde sirasıyla lisans $(\% 45,71)$, yüksek lisans $(\% 34,29)$ ve lise şeklinde sıralanmıştır. Doktora düzeyinde sadece bir personel istihdam edilmiştir.

Ar-Ge personelinin kadın ve erkek olarak dağılımı incelendiğinde lisans düzeyinde erkek sayısı kadın sayısından fazla olurken, yüksek lisans düzeyinde kadın Ar-Ge personeli sayısının erkek Ar-Ge personeli sayısından yüksek olduğu görülmektedir. Bu işletmelerde doktoralı tek Ar-Ge personelinin ise kadın olduğu görülmektedir.

\begin{tabular}{|c|c|c|c|c|c|c|}
\hline \multicolumn{7}{|c|}{ İşletmelerde Tüm Çalışanların Eğitim Durumu } \\
\hline \multirow[b]{2}{*}{ Eğitim Düzeyi } & \multicolumn{2}{|c|}{ Kadın } & \multicolumn{2}{|c|}{ Erkek } & \multicolumn{2}{|c|}{ Toplam } \\
\hline & Kişi & Yüzde (\%) & Kişi & Yüzde (\%) & Kişi & Yüzde (\%) \\
\hline İlkokul & 57 & 30,16 & 94 & 26,7 & 151 & 27,91 \\
\hline Orta öğretim & 80 & 42,32 & 135 & 38,35 & 215 & 39,74 \\
\hline Lise & 34 & 17,99 & 79 & 22,44 & 113 & 20,89 \\
\hline Ön Lisans & 4 & 2,11 & 5 & 1,42 & 9 & 1,66 \\
\hline Lisans & 8 & 4,24 & 30 & 8,52 & 38 & 7,02 \\
\hline Yüksek Lisans & 5 & 2,65 & 9 & 2,56 & 14 & 2,59 \\
\hline Doktora & 1 & 0,53 & 0 & 0 & 1 & 0,18 \\
\hline Toplam & 189 & 100 & 352 & 100 & 541 & 100,00 \\
\hline \multicolumn{7}{|c|}{ İşletmelerde Çalışan Ar-Ge Personellerinin Eğitim Durumu } \\
\hline \multirow[b]{2}{*}{ Eğitim Düzeyi } & \multicolumn{2}{|c|}{ Kadın } & \multicolumn{2}{|c|}{ Erkek } & \multicolumn{2}{|c|}{ Toplam } \\
\hline & Kiși & Yüzde (\%) & Kiși & Yüzde (\%) & Kiși & Yüzde (\%) \\
\hline İlkokul & 0 & 0 & 2 & 3,4 & 2 & 2,86 \\
\hline Orta öğretim & 1 & 9,1 & 2 & 3,4 & 3 & 4,29 \\
\hline Lise & 0 & 0 & 7 & 11,8 & 7 & 10,00 \\
\hline Ön Lisans & 0 & 0 & 1 & 1,7 & 1 & 1,43 \\
\hline Lisans & 4 & 36,4 & 28 & 47,5 & 32 & 45,71 \\
\hline Yüksek Lisans & 5 & 45,4 & 19 & 32,2 & 24 & 34,29 \\
\hline Doktora & 1 & 9,1 & 0 & 0 & 1 & 1,43 \\
\hline Toplam & 11 & 100 & 59 & 100 & 70 & 100 \\
\hline
\end{tabular}

Tablo 1. Işsletmelerde Toplam Çalışanların ve Ar-Ge Personelinin Eğitim Durumuna Göre Dağllımı

Seçilen işletmelerde Ar-Ge çalışanların herhangi bir Ar-Ge eğitimi alıp almadığg sorulmuştur ve \%13,73'ünün Ar-Ge eğitimi aldığı, \%86,27'sinin ise almadığı görülmüştür (Tablo 2). 


\begin{tabular}{|l|l|l|}
\hline Ar-Ge Eğitimi Alma Durumu & Kiși & Yüzde (\%) \\
\hline Eğitim Alındı & 21 & 13,73 \\
\hline Eğitim Alınmadı & 132 & 86,27 \\
\hline Toplam & 153 & 100 \\
\hline
\end{tabular}

Tablo 2. Ar-Ge Ĕ̆itimi Alma Durumu

Seçilen işletmelere devlet tarafından verilen Ar-Ge destekleri hakkında işletme çalışanlarının bilgi sahibi olup olmadığı sorulduğunda \%19'u bilgi sahibi olduğunu \%81'i ise bilgi sahibi olmadığını ifade etmiştir. İşletme çalışanlarının verilen Ar-Ge destekleri hakkında bilgi sahibi olması ile durumu Ar-Ge çalışmalarında bulunma durumu birlikte incelendiğinde, değişkenler arasında farklılıkların istatistiksel bakımdan önemli olduğu sonucuna varılmıştır $(\mathrm{P}<0,05)$. Tablo 3. incelendiğinde Ar-Ge çalışmalarına verilen destekler hakkında bilgi sahibi olan işletmelerin Ar-Ge çalışması yapma oranı \%82,7'iken, bilgi sahibi olmayan işletmelerde bu oranın \%11,3'e düştüğü görülmüştür.

\begin{tabular}{|l|l|l|l|l|}
\hline $\begin{array}{l}\text { Ar-Ge Çalıșmalarına Verilen Destekler Hakkında } \\
\text { Bilgi Sahibi Olma }\end{array}$ & \multicolumn{2}{|l|}{ Bilgi Sahibi Olan } & \multicolumn{2}{l|}{ Bilgi Sahibi Olmayan } \\
\hline Ar-Ge Çalıșması Yapma & Kiși & Yüzde (\%) & Kiși & Yüzde (\%) \\
\hline Yapan & 24 & 82,7 & 14 & 11,3 \\
\hline Yapmayan & 5 & 17,3 & 110 & 88,7 \\
\hline Toplam & 29 & 100 & 124 & 100 \\
\hline$\chi^{2}=64,307 ;$ P Değeri= 0,00 & \multicolumn{4}{l}{} \\
\hline
\end{tabular}

Tablo 3. Ar-Ge Destekleri Hakkında Bilgi Sahibi Olma ve Ar-Ge Yapma Durumu Arasındaki İlişki

\section{2 İşletmelerin Yapısal Durumları ve Nitelikleri İle İlgili Bulgular}

Bu bölümde işletmelerin kuruluş yılı, çalışan sayısı, marka ve tescil durumu gibi kriterler ile Ar-Ge potansiyeli arasındaki ilişkiler tespit edilmeye çalışılmıştır. Araştırma yapılan işletmeler kuruluş yılları itibarıyla incelendiğinde \%35,29'u 1965-2004 yılları arasında, \%64,71'i 2004 yılı sonrasında kurulmuştur. İşletmelerin genelde 2004 yılı sonrası kurulmuş olması işletmelerin henüz genç işletmeler olduğunu göstermektedir.

\begin{tabular}{|l|l|l|}
\hline Yıllar & Sayı & $\mathbf{( \% )}$ \\
\hline $1965-2004$ & 54 & 35,29 \\
\hline$>2004$ & 99 & 64,71 \\
\hline Toplam & 153 & 100 \\
\hline Min=1965, Mak=2015, Ort=2004, S. Sapma=9,6 \\
\hline
\end{tabular}

Tablo 4. İşletmelerin Kuruluş Yılları

Seçilen işletmelerin çalışan sayısına göre dağılımları ise Tablo 5 'de verilmiştir. Tabloya göre işletmelerin büyük çoğunluğunda $(\% 93,46)$ çalışan sayısının 2 kişiden fazla 23 kişiden az, \%6,54'ünde ise 23 kişiden fazla 75 kişiden az olduğu tespit edilmiştir. Anket yapılmak üzere seçilen işletmelerde çalışan sayısının az olması bu işletmelerin küçük ve orta ölçekli işletmeler olduğunu ifade eden göstergelerdendir.

\begin{tabular}{|l|l|l|}
\hline Çalıșan Sayısı Aralığı & Sayı & \multicolumn{1}{c|}{$(\mathbf{)})$} \\
\hline $2-23$ & 143 & 93,46 \\
\hline $23-75$ & 10 & 6,54 \\
\hline Toplam & 153 & 100 \\
\hline Min=2, Max=75, Ort=23,6, S.Sapma=21,1 \\
\hline
\end{tabular}

Tablo 5. İşletmelerin Çalışan Sayısına Göre Dă̆ılımı

İşletmede çalışan personel sayısı ile işletmede Ar-Ge çalışması yapılma durumu beraber incelendiğinde, üzerinde durulan özellik bakımından değişkenler arasındaki farkların istatistiksel olarak önemli olduğu görülmüştür $(\mathrm{P}<0,05)$. Tablo 6. incelendiğinde personel sayısı 8 kişiden az olan işletmelerin \% \%,6'sı Ar-Ge çalışmlarında bulunmakta iken çalışan sayısı 8 kişiden fazla olan işletmelerin Ar-Ge yapma oranı \% 85,2 dir. Bu durum çalışan sayısı ile Ar-Ge yapma durumu arasında pozitif bir ilişki olduğunu göstermektedir.

\begin{tabular}{|l|l|l|l|l|}
\hline İșletmede Ar-Ge Personel Sayısı & $\mathbf{1 - 8}($ Kiși) & \multicolumn{2}{l|}{ (Kiși) } \\
\hline Ar-Ge Yapma Durumu & Kişi & $(\%)$ & Kiși & $(\%)$ \\
\hline Yapan & 9 & 7,6 & 29 & 85,2 \\
\hline Yapmayan & 110 & 92,4 & 5 & 14,8 \\
\hline Toplam & 119 & 100 & 34 & 100 \\
\hline$\chi^{2}=85,590 ;$ P Değeri= 0,000 & \multicolumn{4}{|l}{} \\
\hline
\end{tabular}

Tablo 6. İşletmelerde Çalışan Sayısı İle Ar-Ge Yapma Durumu Arasındaki İlişki

Anket yapılan işletmelerde işletmeye ait web sayfalarının bulunup bulunmadığı sorusuna verilen cevaplar incelendiğinde işletmelerin \%19,61'inin web sayfasının bulunduğu, \%80,9'unun web sayfasının bulunmadığı 
sonucuna ulaşılmıştır (Tablo 7). Bu durum işletmelerin çoğunluğunun günümüz teknoloji koşullarına uyum sağlayamadığını ifade etmektedir.

\begin{tabular}{|l|l|l|}
\hline Web Sayfası Bulunma Durumu & Sayı & Yüzde (\%) \\
\hline Bulunanlar & 30 & 19,61 \\
\hline Bulunmayanlar & 123 & 80,39 \\
\hline Toplam & 153 & 100 \\
\hline
\end{tabular}

Tablo 7. Işletmelerin Web Sayfaları Bulunma Durumu

Çalışmada incelenen işletmelerdeki işletme kuruluş yılının Ar-Ge niteliğinde proje gerçekleştirme üzerine etkisi incelendiğinde, üzerinde durulan özellik bakımından değişkenler arasındaki ilişki istatistiksel olarak önemli olduğu görülmüştür $(\mathrm{P}<0,05)$. Tablo 8'den de görüldüğü gibi 1965-2004 yılları arasında kurulan işletmelerden, $\% 20,4$ 'ü Ar-Ge niteliğinde proje gerçekleştirmiş, \%79,6'sı proje gerçekleştirmemiştir. 2004 yılı sonrasında kurulan işletmelerin ise \%9,1'i proje gerçekleştirmiş, \%90,9'u proje gerçekleştirmemiştir. Bu sonuçlar işletme tecrübesi olan yani daha uzun yıllardır faaliyet gösteren işletmelerin Ar-Ge proje ve uygulamalarında daha başarılı olduğunu ifade etmektedir. Diğger bir deyişle 2004'ten önce kurulan işletmeler, 2004'ten sonra kurulanlara göre daha fazla Ar-Ge çalışması yapmaktadır.

\begin{tabular}{|l|l|l|l|l|}
\hline İșletmenin Kuruluș Yılı & $\mathbf{1 9 6 5 - 2 0 0 4}$ & $\mathbf{> 2 0 0 4}$ \\
\hline Ar-Ge Niteliğinde Proje Yapma & Say1 & $(\%)$ & Say1 & $(\%)$ \\
\hline Proje Yapan & 11 & 20,4 & 9 & 9,1 \\
\hline Proje Yapmayan & 43 & 79,6 & 90 & 90,9 \\
\hline Toplam & 54 & 100 & 99 & 100 \\
\hline$\chi^{2}=3,912 ;$ P Değeri $=0,048$ & \multicolumn{5}{|l|}{} \\
\hline
\end{tabular}

Tablo 8. İşletmelerin Kuruluş Yılı İle Ar-Ge Projesi Yapma Durumu Arasındaki İlişki

İşletme kuruluş yılının işletme bünyesinde ayrı bir Ar-Ge departmanın bulunması üzerine etkisi araştırıldığında üzerinde durulan özellik bakımından değişkenler arasındaki farklılıkların istatistiksel bakımdan önemli olduğu sonucuna varılmıştır $(\mathrm{P}<0,05)$. Yapılan inceleme kapsamında 1965-2004 aralığındaki yıllarda kurulan işletmelerin \%20,4'ünde işletme bünyesinde ayrı bir Ar-Ge departmanı bulunmakta, 2004 y1lı ve sonrasında kurulan işletmelerin ise sadece \%8, '’inde Ar-Ge departmanı bulunmaktadır.

\begin{tabular}{|l|l|l|l|l|}
\hline İșletme Kuruluș Yılı & $\mathbf{1 9 6 5 - 2 0 0 4}$ & $\mathbf{2 0 0 4}$ \\
\hline Ar-Ge Departmanı Bulunma Durumu & Say1 & $(\%)$ & Say1 & $(\%)$ \\
\hline Birim Bulunan & 11 & 20,4 & 8 & 8,1 \\
\hline Birim Bulunmayan & 43 & 79,6 & 91 & 91,9 \\
\hline Toplam & 54 & 100 & 99 & 100 \\
\hline$\chi^{2}=4,852 ;$ P Değeri $=0,028$ & \multicolumn{4}{|l}{} \\
\hline
\end{tabular}

Tablo 9. İşletmelerin Kuruluş Yılı İle Ar-Ge Departmanı Bulunma Durumu Arasındaki İlişki

Anket yapılan işletmelere marka ve tescil durumları sorulduğunda 39 işletme marka ve tescilinin mevcut olduğunu 114 işletme ise mevcut olmadığını ifade etmiştir. Çalışmada incelenen işletmelerde Marka Tescilinin ArGe çalışmalarında bulunma ile ilişkisi araştırıldığında üzerinde durulan nitelik bakımından değişkenler arasındaki farklılıkların istatistiksel bakımdan önemli olduğu sonucuna varılmıştır $(\mathrm{P}<0,05)$. Marka tescilinin varlığı ile ArGe çalışması yapma arasında pozitif bir ilişki olduğu görülmektedir. Nitekim marka tescili olan firmalarda Ar-Ge yapma oranı \%84,6 iken, marka tescili olmayanların Ar-Ge yapma oranı \%4,4 olarak tespit edilmiştir (Tablo 10). Bu sonuçtan hareketle marka tescili bulunan işletmelerin Ar-Ge çalışmalarında bulunmaya daha eğilimli olduğu görülmektedir.

\begin{tabular}{|l|l|l|l|l|}
\hline Tescilli Marka Durumu & Marka Tescili Mevcut & \multicolumn{2}{l|}{ Marka Tescili Mevcut } \\
\hline Ar-Ge Çalıșmalarında Bulunma & Sayı & $(\%)$ & Sayı & $(\%)$ \\
\hline Çalışmada Bulunan & 33 & 84,6 & 5 & 4,4 \\
\hline Çalışmada Bulunmayan & 6 & 15,4 & 109 & 95,6 \\
\hline Toplam & 39 & 100 & 114 & 100 \\
\hline$\chi^{2}=100,195 ;$ P Değeri= $=0,000$ & \multicolumn{4}{|l}{} \\
\hline
\end{tabular}

Tablo 10. Marka ve Tescilin Varlı̆̆ı İle Ar-Ge Çalışmasında Bulunma Durumu Arasındaki İlişki

\section{Sonuç ve Öneriler}

Tarımsal ürün çeşitliliği bakımından zengin ve verimli topraklara sahip Çanakkale ekonomisinde tarımın yeri önemlidir. İlde tarıma dayalı sanayinin gelişme potansiyeli olmasına rağmen bu konuda istenilen düzeye gelinememiştir. Mevcut tarıma dayalı sanayi işletmeleri küçük ve orta ölçekli, kuruluş zamanı bakımından yeni ve Ar-Ge çalışmalarının yeterince yapılmadığı işletmeler konumundadır. Bu durum öncelikle bölgesel üretim potansiyelinin yeterince değerlendirilememesi, bölgesel istihdama katkı sağlayamama ve üretimden sağlanan 
katma değerin il dışına kaymasına neden olmaktadır. Bu şartlar ilde bulunan tarıma dayalı sanayi işletmelerinin iç ve dış pazardaki rekabet şansını azaltmaktadır.

Çalışmada Güney Marmara Kalkınma Ajansı tarafından desteklenen "Çanakkale İlinde Sanayi Envanterinin Oluşturulması, İl Sanayisinin Ar-Ge, Yenilikçilik ve Kümelenme Potansiyelinin Araştırılması Projesi” kapsamında oluşturulan sanayi veri tabanından tarımla ilgili olanlar arasında bir örnekleme yapılmış olup 153 işletme ile anket yapılmıştır. Anketlerden elde edilen sonuçlara göre bu işletmelerde çalışan personelin sadece \%13'ü Ar-Ge personelidir. Ar-Ge personelinin büyük çoğunluğu lisans düzeyinde eğitim almış olup $(\% 45,71)$ bunu yüksek lisans takip etmektedir $(\% 34,29)$. Ar-Ge personeli içerisinde doktora yapma oranı ise sadece $\% 1,43$ 'dür.

Tarıma dayalı sanayi işletmelerin \%86'sı işletmeleri bünyesinde herhangi bir Ar-Ge eğitimi yapılmadığını ifade etmiştir. İşletmelerin sadece \%20'si kurumsal web sayfasına sahiptir.

İşletmelerin \%65'i 2004 yılından sonra kurulmuş olup, bu işletmelerin \%93'ünde çalışan sayısı 23 kişiden daha azdır. Bu değerlerin işletmelerin yeni kurulmuş, küçük ve orta ölçekli işletmeler olduğunu göstermektedir.

Araştırma bulgularına göre kuruluş yılı ile Ar-Ge projesi yürütme arasındaki ilişki, yine kuruluş yılı ile Ar-Ge departmanı bulunma arasındaki ilişkiler incelendiğinde istatistiki olarak anlamlı bir ilişki tespit edilmiştir. Yine Ar-Ge destekleri hakkında bilgi sahibi olmayla Ar-Ge faaliyeti yapma arasında istatistiki olarak anlamlı ilişki tespit edilmiştir. Çalışmadan elde edilen bir başka bulgu ise marka ve tescili olan durumu ile Ar-Ge faaliyeti yapma arasında istatistiki olarak anlamlı ilişki olduğudur.

Dolayısıyla gıda üretim-tüketim zincirinin başlangıç noktasını oluşturan tarım alanında, kişi başına düşen tarım arazisi miktarları son yıllarda özellikle artan nüfusa bağlı olarak ciddi oranda düşmeye başlamıştır. Bu nedenle önümüzdeki dönemde var olan tarım topraklarının verimliliğini arttıracak çalışmaların yapılması oldukça önem arz etmektedir. Bir taraftan birim alandan ve birim hayvandan elde edilecek verimliliği artırmak, diğer taraftan tarıma dayalı sanayinin geliştirilmesi açısından tarım Ar-Ge ilişkisi geliştirilmesi ve incelenmesi gereken bir konudur.

Tarımsal üretimdeki büyüme, belirli ölçüde bilimsel ve teknolojik gelişmelerden faydalanabilme olanaklarına bağlıdır. Diğer taraftan, tarım ve tarıma dayalı sanayi işletmelerinin rekabet avantajı sağlamada fiyat, kalite ve maliyet kadar, yeni ürün geliştirmeye de önem vermeleri gerekmektedir. Yapılacak Ar-Ge çalışmalarıyla tarım ve tarıma dayalı sanayi sektörlerinde üretim, verim ve katma değer daha da arttırılabilecektir.

$\mathrm{Bu}$ bağlamda tarıma dayalı sanayi işletmelerinde Ar-Ge bilincinin artırılması, Ar-Ge teşvik ve destekleri konusunda farkındalığın artırılması, işletmelerin markalaşma konusunda teşvik edilmesi, mevcut personelin ArGe konusunda eğitilmesi ve Ar-Ge tecrübesi olan kişilerin istihdamının artırılması bu çalışma kapsamında sunulabilecek önerilerdir. Bu önerilerin gerçekleşmesinde üniversitelerle ve Gıda, Tarım ve Hayvancılık Bakanlığının Araştırma Enstitüleri ile işbirliği son derece önemlidir.

\section{Kaynakça}

- Akbulak, Y., Akbulak, S., 2015. “Türkiye'nin Rekabet Gücü Bağlamında Araştırma ve Geliştirme (Ar-Ge) Faaliyetlerinin özendirilmesi. Gündem Dergisi.

- Anonim, 2013. "3. Sanayi Şurası Komisyon Raporları” Bilim Sanayi ve Teknoloji Bakanlığı. Ankara.

- Anonim, 2015a. "Bakanlık Ar-Ge Çalışmaları" Gıda, Tarım ve Hayvanclık Bakanlığı, Tarımsal Araştırmalar ve Politikalar Genel Müdürlüğ̈̈, Ankara. Erkek, D. (2011), “Ar-Ge, İnovasyon ve Türkiye”, http://geka.org.tr (Erişim Tarihi: 25.06.2016).

- Anonim, 2015b. "Çanakkale İlinde Sanayi Envanterinin Oluşturulması, İl Sanayisinin Ar-Ge, Yenilikçilik ve Kümelenme Potansiyelinin Araştırılması Projesi” Güney Marmara Kalkınma Ajansı, Çanakkale.

- Anonim, 2016a. "Innovation, Agricultural Productivity and Sustainability in Turkey" OECD Food and Agricultural Reviews.

- Anonim, 2016b. "Temel İstatistikler" http://www.tuik.gov.tr/UstMenu.do?metod=temelist. (Erişim Tarihi: 24.03.2017).

- Anonim, 2016c. "2016 Brifing Raporu” Gıda, Tarım ve Hayvancılık Bakanlığı :anakkale İl Müdürlüğü.

- avak, Ç., 2009. “Bilgi Ekonomisinde İnovasyon Kavramı ve Temel Göztergeleri”, Akademik Bilişim’09 XI. Akademik Bilişim Konferansı Bildirileri, s: 617-628, Harran Üniversitesi, Şanlıurfa.

- Demirbaş, N., (2004). Ege Bölgesi'nde Tarıma Dayalı Sanayinin Yeri ve Önemi, Ege Üniversitesi Ziraat Fakültesi Dergisi, 41(3), 29-48. İzmir.

- Erkek D., 2011. Ar-Ge, İnovasyon ve Türkiye, (Erişim tarihi: 25.03.2017).

- Miran, B., 2002. “Temel İstatistik”, Ege Üniversitesi Basımevi, İzmir. 